\section{OPEN $\bigcirc$ ACCESS}

\title{
Effect of Customer Experience Quality on Loyalty in Fitness Services in Fitness Services
}

Authors' contribution:

A) conception and design of the study

B) acquisition of data

C) analysis and interpretation of data

D) manuscript preparation

E) obtaining funding

Received: 26.04 .2021

Accepted: 30.12 .2021

\author{
Ersin Eskiler ${ }^{*}$ A-E (D), Furkan Safak ${ }^{2 B, D, E}$ (ii) \\ ${ }^{1}$ Sakarya University of Applied Science, Faculty of Sport Science, Department of Sport \\ Management, Sakarya, Turkey \\ ${ }^{2}$ Sakarya University of Applied Science, Graduate Education Institute, Sakarya, Turkey
}

*Correspondence: Ersin Eskiler, Sakarya University of Applied Science, Esentepe Campus 54050 Sakarya/Turkey; email: eeskiler@gmail.com

\begin{abstract}
Customer experience quality is an important and relatively new concept for service businesses in gaining a sustainable competitive advantage. Although the literature on customer experience quality is expanding, there is a gap concerning the antecedent and consequences of customer experience in fitness services. In this context, we tested a model that explains the precursors and implications of customer experience quality in the context of fitness services. This study was based on a non-experimental, depictive, and descriptive design. Within the scope of this study, 287 participants (216 male, 71 female) selected through a convenience sampling technique applied a self-administered questionnaire. Data were analyzed through confirmatory factor analysis and a structural equation model. The findings show that service result quality, customer-employee interaction quality, and customer-customer interaction quality affect customer experience quality, which in turn affects customer loyalty. These results show that improving the service outcome quality results in customers who experience high-quality customer-employee and customer-customer interactions becoming loyal customers.
\end{abstract}

Keywords: Interaction quality, experience quality, customer loyalty, fitness services.

\section{Introduction}

The health and fitness industry has been one of the fastest-growing industries worldwide over the last decade. According to the International Health, Racquet \& Sportsclub Association (IHRSA), this global "movement" generated industry revenue of approximately EUR 79.7 billion in 2019, serving more than 184 million members in more than 210,000 health and fitness facilities (IHRSA, 2020). Similarly, the European health and fitness industry, which includes 28 European Union member countries as well as Norway, Russia, Switzerland, Ukraine, and Turkey, continues to grow systematically (the market grew by $3.0 \%$ to EUR 28.2 billion, in 2019). The number of fitness customers of the European health and fitness industry has increased by $72 \%$ ( 64.8 million members) in the last 10 years (Deloitte, 2020). Germany and the United Kingdom are Europe's largest national health and fitness markets in terms of income and membership (Deliotte, 2020; IHRSA, 2020). On the other hand, Turkey has substantial market potential, with a penetration rate of $8 \%$ and $2.6 \%$ growth (Deloitte, 2019). One of the most significant reasons for 
the positive developments in the health and fitness field is the change in and improvement of Generation Y's sports habits (e.g., increase in income and membership numbers). However, almost $50 \%$ of the adult population (Baby Boomer and Generation X) currently lead a sedentary lifestyle, with over $60 \%$ estimated to be overweight (Batrakoulis, 2019). Apart from demonstrating that the sector still has considerable growth potential (Eskiler \& Altunisik, 2021), this also places significant obligations on companies to attract new customers and maintain existing ones. In other words, it is crucial to support and increase customer engagement through a positive exercise experience and customer experience.

Firms are moving from the traditional marketing of features and benefits to creating experiences for their customers. Today, experiences are the basic building blocks of the exchange process (Schmitt, 1999; Prahalad \& Ramaswamy, 2004). Creating a superior customer experience and ensuring its sustainability now seems to be one of the main goals of service companies (e.g., fitness centers). Within the framework of strategic marketing management, many companies have adopted the concept of customer experience management and included this concept in their mission statements (Verhoef, Lemon, Parasuraman, Roggeveen, Tsiros, \& Schlesinger, 2009). As a matter of fact, offers such as commodities, goods, and services are no longer sufficient for long-term profitability under the current competitive conditions, but these offers are meaningful when presented alongside experiences (Cetin \& Dincer, 2014; Pine \& Gilmore, 1999). Schmitt (1999) states that customer experience results from direct observation of or participation in various events (before, during, and after purchasing). According to Meyer and Schwager (2007), this experience is strictly personal and is associated with a client's interest at different levels (rational, emotional, sensory, physical, and spiritual) as a result of their interaction with a product, firm, or part of its organization (Walls, 2009). Furthermore, consumer experience is holistic in nature (Verhoef et al., 2009), encompassing cognitive and emotional assessments of both direct and indirect interactions with the company that affect the customer's purchasing behavior (Klaus \& Maklan, 2013).

In the literature, the concept of customer experience is considered and defined by different industry experts in diverse ways. In summary, the concept of customer experience can be considered a phenomenon that develops as the consumer interacts with the service provider (e.g., while exercising) and then leads to perceptions of service quality (Gronroos, 1988). Indeed, experiences create unique value for customers, are difficult to imitate, and strongly affect consumer satisfaction, loyalty, and recommendation behavior (Funk, 2017; Pine \& Gilmore, 1999). In this context, customer experience quality (CEQ) is likely to determine the perceived value of the service (Kim \& Choi, 2013), and researchers have found that CEQ has a significant effect on consumers' cognitive and emotional purchasing behavior (Cetin \& Dincer, 2014). Some studies show that providing a superior customer experience is one way to achieve successful marketing results and competitive advantages (Cetin \& Dincer, 2014; Gao, Melero-Polo, \& Sese, 2020; Kim \& Choi, 2013; Klaus \& Maklan, 2013; Verhoef et al., 2009). However, no study has been conducted to empirically test the precursors and results of CEQ in fitness services. Moreover, although CEQ has received significant attention in recent years, creating and managing experiences is still among the biggest challenges for the fitness industry as in other service industries (Cetin \& Dincer, 2014; Walls, Okumus, Wang, \& Kwun, 2011). Fitness centers offer an experience intensive service. Customers (members) see the quality of output (technical quality) and the quality of their interactions with service providers and other customers as part of their experience. Indeed, experiences are not universally the same in various service contexts. In particular, consumer behavior for fitness services should also take into account behaviors that drive members hedonically and emotionally, rather than purely rational models (Cetin \& Dincer, 2014). In addition to this conceptual approach, it can be stated that more studies are needed for consumer experience considering the rapid progress and competitiveness in the fitness industry (Baena-Arroyo, Gálvez-Ruiz, Sánchez-Oliver, \& Bernal-García, 2016; García-Fernández, Gálvez-Ruiz, Sánchez-Oliver, Fernández-Gavira, Pitts, \& Grimaldi-Puyana, 2020). As a result of the relevant literature review, the conceptual analysis of service outcome quality (SOQ), customer-employee interaction quality (CEIQ), and customer-customer interaction quality (CCIQ) suggested by Verhoef et al. (2009) and tested by Kim and Choi (2013) constitutes the starting point of this research. In this context, the aim of the study was to test the structural relationships between the customer experience in a hedonic environment (i.e., fitness services), SOQ, CEIQ, CCIQ, and customer loyalty (CL). Additionally, we aimed to contribute to the knowledge and theory of CEQ specific to fitness services. Therefore, our results provide fitness center managers with a better understanding of the quality perceptions attributed to members and the outputs of CEQ.

\section{Literature review and hypotheses development}

Holbrook and Hirschman (1982) generally state that consumption should be seen as an experience that includes a continuous flow of fantasies, emotions, entertainment, and different customer perceptions (Jain, Aagja, \& 
Bagdare, 2017). In this context, customer experience includes various entertainment activities, sensory pleasures, dreams, aesthetic pleasure, and emotional responses (Holbrook \& Hirschman, 1982). According to Walls (2009), experiences have unique and personal qualities that occupy them emotionally and are remembered, require the perception and participation of the customer, and can be shared with others. Similarly, exercising has cognitive and emotional benefits, such as enhancing one's life experiences, promoting fun, enabling self-realization, and recharging one's life energy. In this state, the benefits obtained from exercise are subjective and related to personal experiences (Baena-Arroyo, García-Fernández, Gálvez-Ruiz, \& Grimaldi-Puyana, 2020; Eskiler, Yildiz, \& Ayhan, 2019). In other words, fitness services as an action, effort, or performance are an experience (Eskiler \& Altunisik, 2019). In this case, the customer experience can be evaluated as enjoyable, interesting, and unforgettable activities and moments (Oh, Fiore, \& Jeoung, 2007) for individuals participating in exercise at a fitness center. Fitness services, like other services, have intangible, inseparable, perishable, and heterogeneous features that cannot be owned, and members pay not only for the core product (fitness membership) but also for "nonrefundable" experiences in the fitness environment (Eskiler \& Altunisik, 2019). Therefore, the participation decision, participation, and consumption action of individuals participating in exercise should be considered integral components of CEQ. Lemke, Clark, and Wilson (2011) state that customer experience consists of three dimensions - communication, service, and usage encounters - while Baena-Arroyo et al. (2020) discuss the service experience as hedonic, social, and utilitarian experiences. On the other hand, Verhoef et al. (2009) and Kim and Choi (2013) conceptualize CEQ as a collective construct, as customer experience is shaped and integrated at all points of interaction with the business. Customers' holistic customer experience perception in the retail world has four essential precursors, according to Verhoef et al. (2009): social environment, service interface, retail store atmosphere, and previous customer experience. Kim and Choi (2013) state that three dimensions (SOQ, CEIQ, and CCIQ) are more important than others in various service types (e.g., those provided by cinemas, bowling alleys, sports centers, and city tours). For this reason, we consider SOQ, CEIQ, and CCIQ as the precursors of CEQ to be achieved in fitness services.

Interactions between the phenomena of service quality and customer satisfaction and the expected repetitive purchasing or loyalty phenomena as a natural result of the interaction and satisfaction among them are critical to sports marketing and have been explored by numerous researchers (e.g., García-Fernández, Gálvez-Ruíz, Pitts, Vélez-Colón, \& Bernal-García, 2018b; Howat \& Assaker, 2013; Walker, Farren, Dotterweich, Gould, \& Walker, 2017). In particular, Oliver (1993) states that satisfaction is a psychological consequence resulting from an experience or emotional response to experiences associated with a purchase. On the other hand, although practitioners see customer experience as a significant factor in creating satisfaction or loyalty, the importance of customer experience has been emphasized in a limited number of studies (Baena-Arroyo et al., 2020; Behnam, Sato, \& Baker, 2021; Kim \& Choi, 2013). The literature can be enriched with such research. Therefore, SOQ is considered as one of the determinants of CEQ in this study. According to Brady and Cronin (2001), SOQ expresses the perceptions of customers regarding the superiority of what they achieve during service encounters (Kim \& Choi, 2013). We argue that there is a positive relationship between SOQ and CEQ provided that the customer experience is considered the subjective response of the customer to holistic direct and indirect encounters with the company (Lemke et al., 2011).

$\mathrm{H}_{1}$ : Customer experience quality is positively affected by the quality of service results as perceived by fitness center customers.

As mentioned before, customer experience is evaluated as a result of interactions between customers and the company (service process), service providers (employees), and other customers. In the interaction between the customer and the employee, the customer experience is entirely personal (Meyer \& Schwager, 2007), and the service provided is not standard because human performance is the essential product (Ko \& Pastore, 2004). In this context, fitness services are a value creation process created through the interaction between the customer and the employee. Indeed, value creation can encourage service reuse in fitness centers, thereby leading to the behavioral loyalty of customers (Behnam et al., 2021). High-quality interactions that enable a fitness client to create unique experiences with their service provider (e.g., trainer) are "key to unlocking new sources of competitive advantage," according to Prahalad and Ramaswamy (2004, p. 7). Moreover, García-Fernández et al. (2020) emphasize the importance of customer-employee relationships and interactions for CL in CrossFit users. Therefore, the quality of the interaction between the customer and the employee (CEIQ) in the process of the co-creation of the experience is vital for both customers (satisfaction, emotional pleasure, stimulation, etc.) and companies (repeat purchasing, positive verbal communication and advice, loyalty, etc.; Akaka, Vargo, \& Schau, 
2015). Lemke et al. (2011) conceptualize CEIQ as the customer's judgments or perceptions of the superiority or excellence of the service provided. Therefore, it is possible to state that the judgments regarding CEIQ are the result of the communication and interactions that take place at multiple contact points, from the first contact with company employees (receptionist, trainer, etc.) to the service delivery and afterward. It is critical that employees exhibit good interaction skills in terms of attitude (importance to their job, etc.), behavior (friendly, polite, etc.), and levels of expertise (knowledge, application skills, etc.) in their interactions with customers (Ko \& Pastore, 2004). As a matter of fact, customers' perception of a high level of interaction quality may accordingly increase the possibility of experiencing a high level of experience quality (Kim \& Choi, 2013). In this context, we argue that there is a positive relationship between CEIQ and CEQ.

$\mathrm{H}_{2}$ : Customer experience quality is positively influenced by the quality of interaction as perceived by fitness center customers.

In many service contexts, customers receive services while other customers are also being served (Wu, 2007). For this reason, fitness services in particular are a social process in which active sports participation is realized and customers affect and interact with each other. According to Kim and Choi (2013), the interaction between customers is a part of their overall experience evaluations. Moreover, a customer's perception of the quality of the service provided can be influenced by other customers' attitudes and behaviors (Brady \& Cronin, 2001; Eskiler \& Altunisik, 2019; Ko \& Pastore, 2004). This situation can be explained with the social influence approach. For example, Gao et al. (2020) state that customer interaction or exposure to the shared experiences of other customers enhances a customer's perception of his or her experience quality with the business. Moreover, it has been stated that the quality of interaction has strategic importance in both group lessons and low-cost fitness centers (GarcíaFernández et al., 2018b, 2020). Nevertheless, a limited number of studies take into account the interaction between customers (Huang \& Hsu, 2010; Kim \& Choi, 2013; Nicholls, 2010; Wu, 2007). Wu (2007) states that customers who are knowledgeable in tourism services can influence other customers' experiences by transferring useful information. Similarly, in the fitness environment, positive communication with other customers, such as situations in which customers help each other, can positively affect customers' service experience. However, the interaction between customers can have a negative effect on experience quality as well. When a customer misdirects another customer in a fitness facility, it may result in athlete injuries or more severe issues. In a sports environment, the inappropriate attitudes and behaviors of customers (speaking loudly, harassing verbally or with eye contact, etc.) may cause negative perceptions and disrupt the customer service experience. In the light of these explanations, we argue that there is a positive relationship between CCIQ and CEQ.

$\mathrm{H}_{3}$ : The quality of interaction between customers as perceived by fitness center customers positively affects the quality of the customer experience.

CL represents a customer's willingness to strive and sacrifice to maintain and improve their relationship with the company. Previous research has used repeat or repurchase and recommendation (engaging in positive verbal communication) intentions as indicators of CL (Amoah, Radder, van Eyk, \& Elizabeth, 2016; Eskiler \& Altunisik, 2021). Although Zeithaml, Berry, and Parasuraman (1996) confirm the link between service quality and CL, customer satisfaction mediates the relationship between service quality and loyalty and customer satisfaction is the primary precursor to CL in later studies (Chen \& Chen, 2010; Cronin, Brady, \& Hult, 2000; García-Fernández et al., 2018a, 2018b, 2020; Howat \& Assaker, 2013). On the other hand, CEQ has been claimed to significantly impact consumers' cognitive and emotional purchasing behavior (Cetin \& Dincer, 2014; Kim \& Choi, 2013; Verhoef et al., 2009). For instance, service experience had a positive effect on behavioral intentions in a study conducted on group and virtual fitness class customers (Baena-Arroyo et al., 2016). According to Pine and Gilmore (1999), successful experiences are those that the customer finds unique, memorable, and sustaining over time, instill a desire to repeat and improve, and spread enthusiastically by word of mouth (Pullman \& Gross, 2004). As such, we propose that CEQ is a precursor of CL and ensures and maintains long-term CL. In this context, companies that offer highquality services (SOQ, CEIQ, and CCIQ) to create pleasant and interesting experiences can increase their CL and achieve successful marketing results.

$\mathrm{H}_{4}$ : Customer loyalty is positively affected by the quality of the customer experience as perceived by fitness center customers.

In the light of the explanations, the conceptual research model in Figure 1 was proposed for this study. 


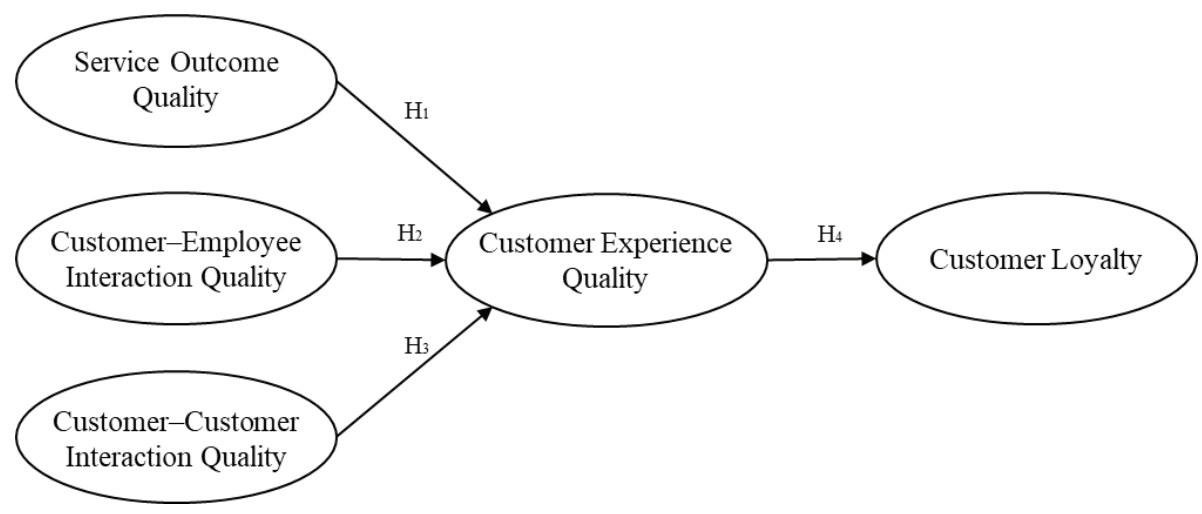

Figure 1. Proposed research model

\section{Method}

This study aimed to test interactions between variables (SOQ, CEIQ, CCIQ, CEQ, and CL) based on a non-experimental, depictive, and descriptive design.

\section{Sample group and procedure}

In the first stage, 19 different fitness centers were contacted and the purpose and scope of the study were explained to each manager. Customers who were members of six different fitness centers and approved the application were included in the study. The data were collected through a questionnaire form applied by the researchers using the easy sampling method on different days and times of the week over four weeks in 2019. It was planned to apply 360 questionnaires in proportion to the number of members in the fitness centers. Participation in the research was voluntary. For this reason, customers were asked if they wanted to participate in the study and were provided brief information about the research at fitness center exits. Of the questionnaire forms distributed, 343 were completed and delivered to the researchers. The surveys took about 7-10 minutes to complete. After the completed questionnaires were examined (fixed signs with the same value, inconsistent marks for control questions, elimination of questionnaires with missing values or errors), a total of 287 were included in the analysis. To acquire an appropriate sample size, the number of participants should be at least 10-20 times the number of items in the scale if multivariate statistical tests are carried out (Hair, Black, Babin, \& Anderson, 2010; Tabachnick \& Fidell, 2007). The sample size/number of items in the current study was $287 / 15$ and provided the minimum criteria specified by the researchers.

Participants were in the $18-45$ age range $(\overline{\mathrm{X}}=23.78 \pm 6.36) ; 75.3 \%(\mathrm{n}=216)$ were male, and $24.7 \%(\mathrm{n}=71)$ were female. Most of the participants, at $53.3 \%(n=153)$, were university graduates; $41.5 \%(n=119)$ were high school graduates; and $5.2 \%(\mathrm{n}=15)$ had a postgraduate degree. The monthly personal income of the participants was $2,300 £-8,000 £(\overline{\mathrm{X}}=2886.34 \pm 1141.22)$. In terms of membership duration, $40.8 \%$ of the participants $(\mathrm{n}=117)$ had a membership for 6 months or less, $37.3 \%(n=107)$ had one for $6-12$ months, $12.5 \%(n=36)$ had one for $1-2$ years, and $9.4 \%(\mathrm{n}=27)$ had one for 2 years or more. An examination of weekly participation times in the centers showed that $2.8 \%$ of the participants $(n=8)$ exercised $1-2$ times a week, $69.9 \%(n=199)$ exercised 3-4 times a week, and $27.9 \%(n=80)$ exercised 5 or more times a week. Furthermore, $17.4 \%(n=50)$ used the fitness center for less than 1 hour per visit, $55.7 \%(\mathrm{n}=160)$ used it for 1 to 2 hours per visit, and $26.8 \%(\mathrm{n}=77)$ used it more than 2 hours per visit. Group lessons (spinning, step aerobics, etc.) were the most popular activity, followed by weight training. The main reasons the participants chose the fitness center were the friendly staff, knowledgeable trainers, adequacy of the physical facilities, program diversity, and cleanliness.

\section{Data collection tools}

In accordance with the purpose of the study, a questionnaire form was created by examining previous studies (Brady \& Cronin, 2001; Kim \& Choi, 2013; Lemke et al., 2011; Mohr \& Bitner, 1995; Zeithaml et al., 1996). This form consisted of three parts. The questionnaire included questions for determining demographic characteristics (gender, age, duration of participation, etc.) and 15 items for measuring research variables. In the first part, nine 
items suggested by Kim and Choi (2013) were included. These nine items are based on the work of Brady and Cronin (2001), Mohr and Bitner (1995), and Lemke et al. (2011). The second part consisted of three-item scales to evaluate CEQ (Brady \& Cronin, 2001; Kim \& Choi, 2013) and CL (Zeithaml et al., 1996). The back-translation method was used to test the language equivalence of the items in the scales. Before the data collection tool was finalized, an expert panel was made to ensure the scope and appearance validity. For possible answers, participants were asked to respond on a five-point Likert scale ranging from "totally disagree" (1) to "completely agree" (5).

\section{Data analysis}

The data were analyzed with the IBM SPSS and AMOS 20 programs. First, descriptive statistics (mean, standard deviation, skewness, kurtosis) were calculated using IBM SPSS 20. The data were checked for normality using the criteria of skewness and kurtosis between \pm 2 (George \& Mallery, 2016) and Mardia's multivariate kurtosis coefficient (Mardia, 1985). The structural equation model (SEM), which is a multivariate analysis method, was used along with other tools for causality analysis in the study. SEM examines the causal relationships between latent variables or between latent variables and observed variables (Hair et al., 2010). First, the maximum probability estimation procedure and confirmatory factor analysis (CFA) were evaluated for the measurement model. A study in which various latent variables were correlated was used to determine the measurement model's construct validity. The reliability of structures was measured using the values of Cronbach's alpha $(\alpha>.70)$ and composite reliability $(C R>$.70) (Hair et al., 2010). Convergent validity were measured by composite reliability, and average shared variance (AVE $>.50 / \mathrm{CR}>\mathrm{AVE}$ ). Discriminant validity was tested through average variance extracted (AVE), maximum shared variance (MSV), and average shared variance (ASV); (MSV < AVE, ASV < AVE) (Fornell \& Larcker, 1981; Hair et al., 2010). CR, AVE, MSV, and ASV values were calculated using Gaskin's Excel-based Statistical Tools Package (Gaskin, 2016). Then, for the current study, a structural model analyzing the predicted relationships between variables was tested. The suitability of the data to the measurement and structural model was evaluated using various fit index values. In this study, the fit index (GFI $\geq 0.95)$, normed fit index (NFI $\geq 95$ ), Tucker-Lewis index ( $\mathrm{TLI} \geq 95$ ), comparative fit index ( $\mathrm{CFI} \geq 0.95$ ), standardized root mean squared residual (SRMR $\leq .05$ ), and the root-mean-square of the prediction errors (RMESA $\leq .05)$ were used as model fit index values, and the Chi-square $\left(\chi^{2} / \mathrm{df}\right)$ test results were reported (Brown, 2006; Hooper, Coughlan, \& Mullen, 2008; Kline, 2015; Tabachnick \& Fidell, 2007). Chi-square values according to degrees of freedom $\left(\chi^{2} / \mathrm{df}\right)$ should be less than 3 (Hooper et al., 2008; Kline, 2015).

\section{Results}

The CFA method was used to verify the structures in the measurement model with the measured expressions. The CFA results showed that the model fit the available data at a satisfactory level $\left(\chi^{2} / \mathrm{df}[160.52 / 80]=2.01\right.$, $\mathrm{SRMR}=.033, \mathrm{RMSEA}=.059[90 \% \mathrm{CI}=.046-.073], \mathrm{GFI}=.93, \mathrm{NFI}=.97, \mathrm{TLI}=.98, \mathrm{CFI}=.98)$. An RMSEA of $.05-.08$ and GFI index value in the range of .95-.90 are indicative of the suitability of an acceptable model (Brown, 2006; Hooper et al., 2008). Therefore, the RMSEA and GFI values were at acceptable levels. On the other hand, having the SRMR value less than .05 and NFI, TLI, and CFI index values above .95 showed that the model had good fit values (Hair et al., 2010; Kline, 2015). Finally, the $\chi^{2}$ statistic was significant $(\mathrm{p}<.01)$, and the ratio of statistics to degrees of freedom was lower than the suggested 3.0 criterion (Hooper et al., 2008; Kline, 2015).

In Table 1, the standardized regression coefficients $(\lambda)$ show the relationship of each item with the relevant structure (factor) and the squares of these coefficients. The standardized regression coefficients of all items were between .803-.943 $(\lambda>.70)$, and the $t$ values ranged between 18.36-29.96, indicating that each item significantly represented its respective structure.

All tests that were used to evaluate the model in terms of reliability and validity are presented in Table 2. Accordingly, Cronbach's alpha (between .910-.948) and CR values (between .917-.949) were over 70, which is the acceptable level (Hair et al., 2010). These values showed that the model was reliable.

The AVE values tested for affinity validity (between .780-.841) were higher than 50, and the CR values were higher than the AVE values (Fornell \& Larcker, 1981; Hair et al., 2010). For the discrimination validity test, AVE values of each factor were compared with MSV (between .450-.738) and ASV values (between .488-.671). Both MSV and ASV values for all factors did not exceed AVE values (Fornell \& Larcker, 1981; Hair et al., 2010). In this case, the findings supported the model's similarity and discrimination validity. Descriptive statistics and interstructural correlations of the variables are summarized in Table 2. According to this information, all structures were 
Table 1. Regression weights, $t$-values, $R^{2}$

\begin{tabular}{|c|c|c|c|c|c|c|}
\hline Construct & Items & Estimates & S.E. & $t$-values & Standardized loadings $(\lambda)$ & $R^{2}$ \\
\hline \multirow{3}{*}{ Service Outcome Quality } & SOQ 1 & 1.000 & - & - & .891 & .794 \\
\hline & SOQ 2 & 1.209 & .049 & 24.777 & .931 & .867 \\
\hline & SOQ 3 & 1.074 & .043 & 24.733 & .928 & .861 \\
\hline \multirow{3}{*}{$\begin{array}{l}\text { Customer - Employee } \\
\text { Interaction Quality }\end{array}$} & CEIQ 4 & 1.000 & - & - & .915 & .837 \\
\hline & CEIQ 5 & 1.019 & .040 & 25.420 & .926 & .857 \\
\hline & CEIQ 6 & .893 & .049 & 18.361 & .803 & .645 \\
\hline \multirow{3}{*}{$\begin{array}{l}\text { Customer - Customer } \\
\text { Interaction Quality }\end{array}$} & CCIQ 7 & 1.000 & - & - & .933 & .871 \\
\hline & CCIQ 8 & .971 & .032 & 29.956 & .943 & .889 \\
\hline & CCIQ 9 & .887 & .034 & 26.432 & .906 & .821 \\
\hline \multirow{3}{*}{$\begin{array}{l}\text { Customer Experience } \\
\text { Quality }\end{array}$} & CEQ 1 & 1.000 & - & - & .909 & .826 \\
\hline & CEQ 2 & .840 & .039 & 21.795 & .864 & .747 \\
\hline & CEQ 3 & 1.025 & .039 & 26.305 & .937 & .878 \\
\hline \multirow{3}{*}{ Customer Loyalty } & CL 1 & 1.000 & - & - & .899 & .808 \\
\hline & CL 2 & .991 & .038 & 26.336 & .943 & .889 \\
\hline & CL 3 & .755 & .040 & 18.657 & .816 & .666 \\
\hline
\end{tabular}

Note: $\chi^{2} / \mathrm{df}_{(160.52 / 80)}=2.01, \mathrm{SRMR}=.033, \mathrm{RMSEA}=.059(90 \% \mathrm{CI}=.046-.073), \mathrm{GFI}=.93, \mathrm{NFI}=.97, \mathrm{TLI}=.98, \mathrm{CFI}=.98$.

Table 2. Descriptive statistics, correlations among the constructs and the results of reliability and validity

\begin{tabular}{|c|c|c|c|c|c|c|c|c|c|c|}
\hline & \multirow{2}{*}{$\alpha$} & \multirow{2}{*}{$\mathrm{CR}$} & \multirow{2}{*}{ AVE } & \multirow{2}{*}{ MSV } & \multirow{2}{*}{ ASV } & \multicolumn{5}{|c|}{ Construct $^{*}$} \\
\hline & & & & & & SOQ & CEIQ & CCIQ & CEQ & $\mathrm{CL}$ \\
\hline SOQ & .938 & .941 & .841 & .702 & .573 & .917 & & & & \\
\hline CEIQ & .909 & .914 & .780 & .602 & .488 & .776 & .883 & & & \\
\hline CCIQ & .948 & .949 & .860 & .450 & .671 & .589 & .550 & .927 & & \\
\hline CEQ & .929 & .930 & .817 & .738 & .589 & .800 & .726 & .671 & .904 & \\
\hline $\mathrm{CL}$ & .910 & .917 & .788 & .738 & .588 & .838 & .722 & .624 & .859 & .888 \\
\hline$\overline{\mathrm{X}}$ & - & - & - & - & - & 5.34 & 5.63 & 5.10 & 5.24 & 5.41 \\
\hline SD & - & - & - & - & - & 1.45 & 1.27 & 1.59 & 1.48 & 1.62 \\
\hline
\end{tabular}

Note: $\bar{X}=$ mean; $\mathrm{SD}=$ standard deviation; SOQ = service outcome quality; CEIQ = customer-employee integration quality; CCIQ = customer-customer interaction quality; CEQ = customer experience quality; CL = customer loyalty. ${ }^{¥}$ Numbers on the diagonal (in bold) represent the square root of the AVE. Off-diagonal numbers represent the correlations among constructs. Reliability $=\alpha>.70$ and $\mathrm{CR}>.70$; Convergent validity $=\mathrm{CR}>\mathrm{AVE}$ and AVE $>.50$; Discriminant validity $=\mathrm{MSV}<\mathrm{AVE}$ and ASVAVE.

moderately and highly positively correlated and statistically significant $(\mathrm{p}<.01)$. SOQ $(\overline{\mathrm{X}}=5.34 \pm 1.45)$ had the highest average, while CCIQ $(\overline{\mathrm{X}}=5.10 \pm 1.59)$ had the lowest average.

The SEM was used to test the relationships and interactions between the variables presented in Figure 1. The first analysis showed that the model fit indices were weaker than expected. The analysis was repeated by performing only one modification within the framework of the modification index values. When the general fit of the post-modification research model was examined $\left(\chi^{2} / \mathrm{df}_{[186.79 / 82]}=2.28, \mathrm{SRMR}=.041, \mathrm{RMSEA}=.067[90 \% \mathrm{CI}=.054-.080]\right.$, $\mathrm{GFI}=.92, \mathrm{NFI}=.96 ; \mathrm{TLI}=.97, \mathrm{CFI}=.98)$, the model was found to fit well with the current data set (Hooper et al., 2008; Kline, 2015), and no other modification was required. 


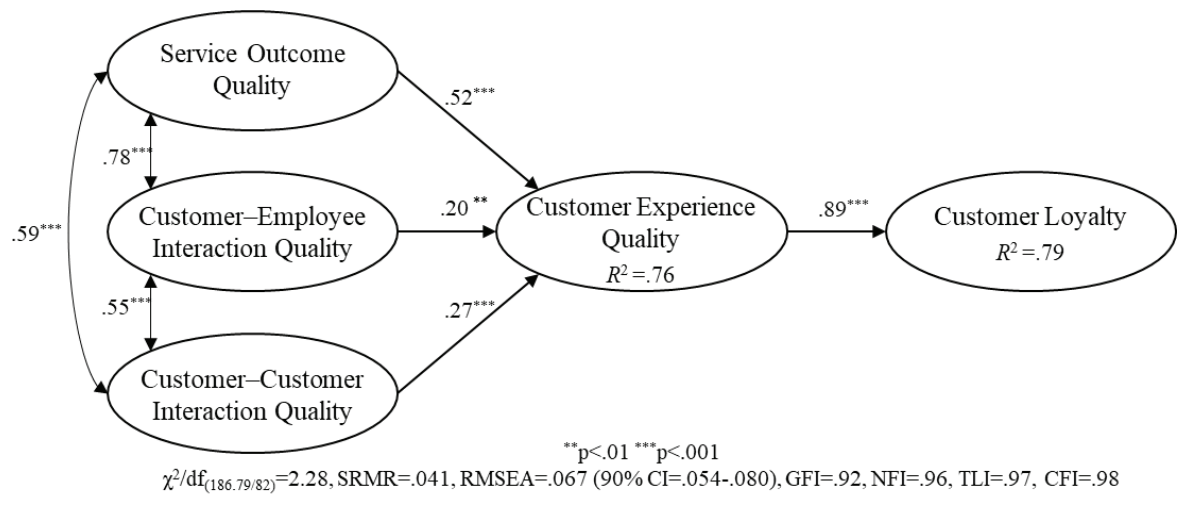

Figure 2. Standardized estimates of the structural model with identified path coefficients

The model depicted in Figure 2 indicates that SOQ $(\beta=.52 ; \mathrm{p}<.001)$, CEIQ $(\beta=.20 ; \mathrm{p}<.01)$, and CCIQ $(\beta=.27 ; \mathrm{p}<.001)$ were positive and significant predictors of CEQ. Therefore, hypotheses $\mathrm{H}_{1}, \mathrm{H}_{2}$, and $\mathrm{H}_{3}$ were confirmed. On the other hand, the correlations between the CEQ determinants SOQ, CEIQ, and CCIQ were positive and significant $(\mathrm{r}=.78, \mathrm{r}=.59, \mathrm{r}=.55 ; \mathrm{p}<.001)$. SOQ, CEIQ, and CCIQ structures explained $76 \%$ of the variance related to CEQ $\left(R^{2}=.76\right)$. In addition, CEQ $(\beta=.89 ; \mathrm{p}<.001)$ predicted CL positively and significantly. This finding revealed that hypothesis $\mathrm{H}_{4}$ was also confirmed. The findings, the CEQ, and the predecessors explained $79 \%$ of the variance related to $\mathrm{CL}\left(R^{2}=.79\right)$.

\section{Discussion}

For years, CL has been one of the most fundamental concepts in long-term business profitability and sustainability. As a matter of fact, perceived quality, perceived value, and satisfaction in both the general service sector (Chen \& Chen, 2010; Cronin et al., 2000) and the fitness sector (García-Fernández et al., 2018a; Howat \& Assaker, 2013) increase CL, and customer satisfaction is the primary precursor of CL. However, over the last decade, researchers have emphasized the importance of creating a superior customer experience (Bueno, Weber, Bomfim, \& Kato, 2019; Fernandes \& Pinto, 2019; Jain et al., 2017; Kim \& Choi, 2013; Lemke et al., 2011; Pullman \& Gross, 2004). Moreover, due to the nature of the fitness industry, creating a superior customer experience is of paramount importance to businesses. However, little effort has been made to examine the premises and results of CEQ. In other words, despite the increasing interest in different sectors (Jain et al., 2017), empirical evidence that CEQ can contribute to CL is quite insufficient. Therefore, the current research analyzes the relationships between SOQ, CEIQ, CCIQ, CEQ, and CL through a holistic model and contributes to the sports marketing literature. In particular, this research expands the literature on the relationships of relevant variables in the sports context and offers various clues for other sectors. The findings show that, in general, fitness customers' perceptions of CEIQ, SOQ, and CCIQ are quite positive. Similarly, it should be emphasized that CEQ perceptions and CL levels have positive and high mean scores.

Findings from fitness center customers reveal that SOQ, CEIQ, and CCIQ are essential precursors of CEQ. In other words, CEQ is influenced by customers' perceptions of service results as well as their interactions with staff and other customers. In addition, consistent with the holistic nature of the customer experience, there was a moderate to high positive relationship between SOQ, CEIQ, and CCIQ. In this case, the variable that had the most critical effect on CEQ was SOQ, followed by CCIQ and CEIQ, respectively. Therefore, the obtained results were consistent with the work of Gao et al. (2020), Klaus and Maklan (2013), and Kim and Choi (2013). Our findings also provided empirical support for the proposition of Verhoef et al. (2009) on the relationship between CCIQ and CEQ.

The high impact of SOQ could result from fitness center customers being primarily concerned with the outcome of the service and their dominant needs (such as being healthy, losing weight, and looking fit) being at the forefront. Our results support the view that customers' perceptions of the superiority of what they achieve (to what extent their expectations are met) during service encounters (Brady \& Cronin, 2001) are important. At this point, in addition to determining customer expectations and designing appropriate exercise programs, the physical environment in which the service is provided and presented can affect the customer experience positively or negatively. For this 
reason, understanding customer expectations correctly and realizing the conditions and practices that will make them feel valuable can make it easier for them to have positive perceptions of experience.

Previous research has placed significant emphasis on creating positive interactions between businesses and customers or employees and customers in general (Kim \& Choi, 2013). Our findings indicate that interactions between service providers and consumers significantly affect CEQ in the fitness industry. The interaction between an employee (e.g., personal trainer) and the customer is unique and is seen by business management as a unique value creation process. According to Berry and Carbone (2007, p. 27), customers consciously or unconsciously perceive or feel the environment through a series of cues and state that everything perceived or felt - or is noticeable in its absence - is a clue to the experience. In this context, employees also contribute various clues and messages to their surroundings. These tips and messages come together to provide customers with unique experiences. Communication should not be a monologue and should promote originality in creating a unique customer experience, as the interaction between each customer and employee will be different. Ko and Pastore (2004) point out the importance of good interaction skills in terms of employees' attitudes, behavior, level of expertise, and so on. Business management can provide in-service training to their employees on how to take into account different customer characteristics and decide on the correct interaction in the framework of these features and how to apply them. In addition, the recruitment process, promotion, employee motivation, empowerment, and retention capability of business professionals are gaining importance. For example, if a fitness instructor does not have the right skills or is not sufficiently motivated or trained, they may have difficulty interacting with customers or may endanger their health. For this reason, it is suggested that enterprises minimize employee turnover in order to achieve high CEI (Cetin \& Dincer, 2014).

CCIQ is the second phenomenon that has the most significant impact on CEQ, and it is the mode of interaction that marketers have the least control over. Through various initiatives (in-service training, etc.), enforcement, implementation, and monitoring for impact can be carried out for CEIQ and SOQ. However, businesses must develop new strategies to manage communication and the interaction between customers or predict their results. As a matter of fact, Pullman and Gross (2004) state that interaction between customers can be a manageable component of service experience design that aims to design unforgettable customer experiences through careful planning of physical and relational elements in the service environment. Preventing adversities that may arise in fitness service environments with high interaction between customers can increase customers' perceptions of the quality of the experience. Emphasizing that CCI has a substantial impact on customer experience, Huang and Hsu (2010) state that developing appropriate interactions between customers can differentiate the marketing strategies of businesses. Heinonen, Jaakkola, and Neganova (2018) state that their CCI is versatile, complex, and related to both proposals and processes. Moreover, dysfunctional and abusive customers in the service environment and a heterogeneous customer base can negatively affect customer experiences (Wu, 2007; Verhoef et al., 2009). For this reason, fitness center managers can encourage collaboration among customers with exercise programs that require teamwork (such as particular interest or group activities) and bring likeminded customers together, especially in the service environment. We anticipate that market segmentation could be planned and implemented correctly within the framework of basic marketing principles to ensure this cooperation. Similarly, Gao et al. (2020) state that online or offline brand communities can be used to encourage interactions and conversations between customers, and these platforms can be reliable sources of information for products and services.

It is a well-known reality that loyal customers make more purchases and are less price sensitive. For this reason, building a loyal customer base is essential in fitness centers as in every business. When the relationship between CEQ and CL was examined, CEQ was an important determinant for CL. In a comparative analysis study of instructor and virtual fitness classes, service experience was one of the important determinants of customer satisfaction and future intentions (such as loyalty, willingness to pay more, and complaints). In this study, empowerment actions that contributed to creating the customer experience led to greater satisfaction and, in turn, CL (Baena-Arroyo et al., 2020). According to Pullman and Gross (2004, p. 553), "properly applied experiences will promote loyalty not only through a functional design but also by creating an emotional connection through an engaging, compelling and coherent context." In this case, when a holistic approach is adopted by taking into account the sum of all direct and indirect interactions in a fitness center, customers will display a positive attitude and thus become more loyal depending on their perception of the quality of the service experience. Likewise, previous studies suggest that consumer experience leads to behavioral loyalty (Baena-Arroyo et al., 2016, 2020; Behnam et al., 2021). Additionally, Srivastava and Kaul (2016) state that customer experience affects both behavioral and attitudinal loyalty in the retail industry, while Roy (2018) notes that customer experience for a hedonic service (restaurant chain) has a greater impact on consumer attitudes than for a utilitarian service (banking). When fitness services are considered largely 
as a sector in the hedonic context (Lemke et al., 2011), it is possible to state that these research findings provide evidence for previous research.

It has been stated that CEQ attracts less attention from business management and researchers according to the concepts of service quality and customer satisfaction (Kim \& Choi, 2013). Moreover, Bueno et al. (2019) state that customer experience studies focus primarily on tourism services (hotels, hotel restaurants, museums, and travel sites), followed by studies on healthcare and retail services, respectively. This study is important for focusing on the precursors and results of CEQ in fitness services. Based on the study findings, more attention could be paid to the precursors of CEQ in fitness services and efforts to create CEQ. In this way, it may be possible for fitness centers to gain a long-term competitive advantage. Customers interact directly and indirectly with the business through many channels and at different times (Funk, 2017). As a matter of fact, Lemke et al. (2011, p. 865-866) state that "The superiority of experience examples from hedonic contexts in the practitioner literature has the advantage of showing that the experience is created together with the business rather than delivered by itself." In support of this view, García-Fernández et al. (2020) emphasize the importance of ease of use of services and immediate solutions to potential problems. In this context, it is recommended that fitness center managers design pleasurable and user-centered interactions in which experiences are created together. Indeed, the authors point out that the customer experience can be gradually built through improvements in SOQ and repeated interactions with the service provider and other customers (Roy, 2018; Verhoef et al., 2009). The creation of a high CEQ as a result of this gradual construction will have positive effects on the development of a loyal customer base and long-term operating profitability. Fitness centers that optimize and effectively manage interactions with customers at all contact points before, during, and after purchasing can increase engagement, revenue, and future purchases and minimize losses by having a loyal customer portfolio (GarcíaFernández, 2020; Pullman \& Gross, 2004).

\section{Limitations and future research}

Our study had some limitations that should be taken into account. The model tested in the study was analyzed using a cross-section data acquisition technique and self-administered questionnaire data. Research results based on an experimental design in which positive and negative experiences could be kept under control could help the results of this study be more clearly understood. The study was restricted to fitness centers that volunteered to participate and participants chosen from among these centers' customers using an easy sampling method. Therefore, national-level conclusions based on the results of the study should be put forward carefully. Research findings may offer insight to both practitioners and academics, but we anticipate that future research may help generalize current findings. As previously reported, Turkey's fitness industry has a rapidly evolving market structure, and consumer perceptions can shift continuously (Eskiler \& Altunisik, 2021). For this reason, it is strategically important to measure consumer demands and expectations in developing markets systematically and to organize business practices in line with this information. Finally, this research included a total of five variables, three CEQ precursors (SOQ, CEIQ, and CCIQ) and one outcome variable (CL). A model can be developed in future studies using different variables. For example, there is a need for studies to determine the relationship between customer experience and business performance or how it affects marketing results such as market share and profitability (Klaus \& Maklan, 2013). This study was conducted with a focus on private fitness centers. Therefore, further studies could be performed in different types of public and private sports facilities or sectoral comparisons could be made with larger sample groups. Lastly, future studies could assess additional factors (e.g., male and female participants, low - and high-cost fitness centers, low and high involvement) (Eskiler \& Altunisik, 2021; García-Fernández, 2018, 2020) as moderating variables.

\section{Conclusion}

This study reveals the positive relationships and interactions between the research variables. Our findings show that customers who perceive a high-quality experience attributable to high CEIQ and CCIQ might also be more likely to become loyal customers thanks to the improvement of SOQ. The results can contribute to the development and improvement of marketing strategies for increasing CEQ in fitness centers, creating the customer experience, and managing the process. Additionally, the findings have implications for fitness center executives or marketing managers who aim to increase CL (or member loyalty) and club effectiveness. 


\section{Competing interests}

There are no potential conflicts of interest.

\section{Funding}

This research received no specific funds from any public or private funding agencies.

\section{References}

Akaka, M. A., Vargo, S. L., \& Schau, H. J. (2015). The context of experience. Journal of Service Management, 26(2), 206-223. https://doi.org/10.1108/JOSM-10-2014-0270

Amoah, F., Radder, L., van Eyk, M., \& Elizabeth, P. (2016). Experience quality dimensions and customer perceptions: A case study of guesthouses in Ghana. African Journal of Hospitality, Tourism and Leisure, 5(4), 1-21.

Baena-Arroyo, M. J., Gálvez-Ruiz, P., Sánchez-Oliver, A. J., \& Bernal-García, A. (2016). The relationship among service experience, perceived value and behavioural intentions of customers in a group fitness class. Revista de psicología del deporte, 25(1), 89-92.

Baena-Arroyo, M. J., García-Fernández, J., Gálvez-Ruiz, P., \& Grimaldi-Puyana, M. (2020). Analyzing consumer loyalty through service experience and service convenience: Differences between instructor fitness classes and virtual fitness classes. Sustainability, 12(3), 828. https://doi.org/10.3390/su12030828

Batrakoulis, A. (2019). European survey of fitness trends for 2020. ACSM's Health \& Fitness Journal, 23(6), 28-35.

Behnam, M., Sato, M., \& Baker, B. J. (2021). The role of consumer engagement in behavioral loyalty through value cocreation in fitness clubs. Sport Management Review, 1-27. DOI: 10.1080/14413523.2021.1880772.

Berry, L. L. \& Carbone, L. P. (2007). Build loyalty through experience. Quality Progress, 40(9), 26-32.

Brady, M. K. \& Cronin, J. (2001). Some new thoughts on conceptualizing perceived service quality: A hierarchical approach. Journal of Marketing, 65, 34-49. https://doi.org/10.1509/jmkg.65.3.34.18334

Brown, T. A. (2006). Confirmatory Factor Analysis for Applied Research. New York, NY: Guilford.

Bueno, E. V., Weber, T. B. B., Bomfim, E. L., \& Kato, H. T. (2019). Measuring customer experience in service: A systematic review. The Service Industries Journal, 39(11-12), 779-798. https://doi.org/10.1080/02642069.2018.1561873

Cetin, G. \& Dincer, F. I. (2014). Influence of customer experience on loyalty and word-of-mouth in hospitality operations. Anatolia, 25(2), 181-194. https://doi.org/10.1080/13032917.2013.841094

Chen, C. F. \& Chen, F. S. (2010). Experience quality, perceived value, satisfaction and behavioral intentions for heritage tourists. Tourism Management, 31(1), 29-35. https://doi.org/10.1016/j.tourman.2009.02.008

Cronin J. J., Brady, M. K., \& Hult, G. T. M. (2000). Assessing the effects of quality, value, and customer satisfaction on consumer behavioral intentions in service environments. Journal of Retailing, 76(2), 193-218.

Deloitte. (2019). European health \& fitness market report. Retrieved January 26, 2021, from https://www2.deloitte.com/ content/dam/Deloitte/es/Documents/acerca-de-deloitte/Deloitte-ES-TMT-European-Health-Fitness-Market-2019.pdf

Deloitte. (2020). European health \& fitness market report. Retrieved January 26, 2021, from https://www2.deloitte.com/ content/dam/Deloitte/de/Documents/consumer-business/European-Health-and-Fitness-Market-2020-Reportauszug. pdf

Eskiler, E. \& Altunisik, R. (2019). Fitness Services and Marketing. Istanbul: Beta Publishing.

Eskiler, E. \& Altunisik, R. (2021). The moderating effect of involvement in the relationship between customer behavioral intentions and its antecedents. Sage Open, 11(2). https://doi.org/10.1177/21582440211014495

Eskiler, E., Y1ld1z, Y., \& Ayhan, C. (2019). The effect of leisure benefits on leisure satisfaction: Extreme sports. Turkish Journal of Sport and Exercise, 21(1), 16-20. https://doi.org/10.15314/tsed.522984

Fernandes, T. \& Pinto, T. (2019). Relationship quality determinants and outcomes in retail banking services: The role of customer experience. Journal of Retailing and Consumer Services, 50, 30-41. https://doi.org/10.1016/j.jretconser.2019.01.018

Fornell, C. \& Larcker, D. F. (1981). Evaluating structural equation models with unobservable variables and measurement error. Journal of Marketing Research, 18(1), 39-50. https://doi.org/10.1177/002224378101800104

Funk, D. C. (2017). Introducing a Sport Experience Design (SX) framework for sport consumer behavior research. Sport Management Review, 20(2), 145-158. https://doi.org/10.1016/j.smr.2016.11.006.

García-Fernández, J., Gálvez-Ruíz, P., Fernández-Gavira, J., Vélez-Colón, L., Pitts, B., \& Bernal-García, A. (2018b). The effects of service convenience and perceived quality on perceived value, satisfaction and loyalty in low-cost fitness centers. Sport Management Review, 21(3), 250-262. https://doi.org/10.1016/j.smr.2017.07.003 
García-Fernández, J., Gálvez-Ruíz, P., Pitts, B. G., Vélez-Colón, L., \& Bernal-García, A. (2018a). Consumer behavior and sport services: An examination of fitness center loyalty. International Journal of Sport Management and Marketing, 18(1-2), 8-23. https://doi.org/10.1504/IJSMM.2018.091342

García-Fernández, J., Gálvez-Ruiz, P., Sánchez-Oliver, A. J., Fernández-Gavira, J., Pitts, B. G., \& Grimaldi-Puyana, M. (2020). An analysis of new social fitness activities: Loyalty in female and male CrossFit users. Sport in Society, 23(2), 204-221. https://doi.org/10.1080/17430437.2019.1625332

Gaskin, J. (2016). Validity master, stats tool package. Retrieved February 20, 2021, from http://statwiki.kolobkreations. com/index.php?title=Main_Page.

Gao, L., Melero-Polo, I., \& Sese, F. J. (2020). Customer equity drivers, customer experience quality, and customer profitability in banking services: The moderating role of social influence. Journal of Service Research, 23(2), $174-193$. https://doi.org/10.1177/1094670519856119

George, D. \& Mallery, P. (2016). IBM SPSS Statistics 23 Step By Step: A Simple Guide and Reference (13 ${ }^{\text {th }}$ ed.). New York, NY: Routledge.

Hair, J., Black, W., Babin, B., \& Anderson, R. (2010). Multivariate Data Analysis. Upper Saddle River, NJ: Pearson Education.

Heinonen, K., Jaakkola, E., \& Neganova, I. (2018). Drivers, types and value outcomes of customer-to-customer interaction: An integrative review and research agenda. Journal of Service Theory and Practice, 28 (6), 710-732. https://doi. org/10.1108/JSTP-01-2017-0010

Holbrook, M. B. \& Hirschman, E. C. (1982). The experiential aspects of consumption: Consumer fantasies, feelings and fun. Journal of Consumer Research, 9(2), 132-140. https://doi.org/10.1086/208906

Hooper, D., Coughlan, J., \& Mullen, M. R. (2008). Structural equation modelling: Guidelines for determining model fit. Electronic Journal of Business Research Methods, 6, 53-60.

Howat, G. \& Assaker, G. (2013). The hierarchical effects of perceived quality on perceived value, satisfaction, and loyalty: Empirical results from public, outdoor aquatic centers in Australia. Sport Management Review, 16, $268-284$. https://doi.org/10.1016/j.smr.2012.10.001

Huang, J. \& Hsu, C. H. (2010). The impact of customer-to-customer interaction on cruise experience and vacation satisfaction. Journal of Travel Research, 49(1), 79-92. https://doi.org/10.1177/0047287509336466

IHRSA. (2020). The 2020 IHRSA global report. Retrieved January 26, 2021, from https://www.ihrsa.org/publications/ the-2020-ihrsa-global-report/.

Jain, R., Aagja, J., \& Bagdare, S. (2017). Customer experience - A review and research agenda. Journal of Service Theory and Practice, 27(3), 642-662. https://doi.org/10.1108/JSTP-03-2015-0064

Kim, H. \& Choi, B. (2013). The influence of customer experience quality on customers' behavioral intentions. Services Marketing Quarterly, 34(4), 322-338. https://doi.org/10.1080/15332969.2013.827068

Klaus, P. \& Maklan, S. (2013). Towards a better measure of customer experience. International Journal of Market Research, 55(2), 227-246. https://doi.org/10.2501/IJMR-2013-021

Kline, R. B. (2015). Principles and Practice of Structural Equation Modeling. New York, NY: Guilford.

Ko, Y. J. \& Pastore, D. L. (2004). Current issues and conceptualizations of service quality in the recreation sport industry. Sport Marketing Quarterly, 13(2), 158-166.

Lemke, F., Clark, M., \& Wilson, J. (2011). Customer experience quality: An exploration in business and consumer contexts using repertory grid technique. Journal of the Academy of Marketing Science, 39, 846-869. https://doi.or$\mathrm{g} / 10.1007 / \mathrm{s} 11747-010-0219-0$

Mardia, K. V. (1985). Mardia's test of multinormality. In Encyclopedia of Statistical Sciences (Vol. 5, pp. 217-221). Hoboken, NJ: Wiley Online Library.

Meyer, C. \& Schwager, A. (2007). Understanding customer experience. Harvard Business Review, 85(2), $116-126$.

Mohr, L. A. \& Bitner, M. J. (1995). The role of employee efforts in satisfaction with service transactions. Journal of Business Research, 32(3), 239-252. https://doi.org/10.1016/0148-2963(94)00049-K

Nicholls, R. (2010). New directions for customer-to-customer interaction research. The Journal of Services Marketing, 24(1), 87-97. https://doi.org/10.1108/08876041011017916

Oh, H., Fiore, A. M., \& Jeoung, M. (2007). Measuring experience economy concepts: Tourism applications. Journal of Travel Research, 46(2), 119-132. https://doi.org/10.1177/0047287507304039

Oliver, R. L. (1993). A conceptual model of service quality and service satisfaction: Compatible goals, different concepts. Advances in Services Marketing and Management, 2(4), 65-85.

Pine, J. B. \& Gilmore, J. H. (1999). The Experience Economy: Work Is Theater and Every Business a Stage. Cambridge, MA: Harvard Business School Press. 
Prahalad, C. K. \& Ramaswamy, V. (2004). Co-creation experiences: The next practice in value creation. Journal of Interactive Marketing, 18(3), 5-14. https://doi.org/10.1002/dir.20015

Pullman, M. E. \& Gross, M. A. (2004). Ability of experience design elements to elicit emotions and loyalty behaviors. Decision Sciences, 35(3), 551-79. https://doi.org/10.1111/j.0011-7315.2004.02611.x

Roy, S. (2018). Effects of customer experience across service types, customer types and time. Journal of Services Marketing, 32(4), 400-413. https://doi.org/10.1108/JSM-11-2016-0406

Schmitt, B. (1999). Experiential marketing. Journal of Marketing Management, 15(1/3), 53-67. https://doi.or$\mathrm{g} / 10.1362 / 026725799784870496$

Srivastava, M. \& Kaul, D. (2016). Exploring the link between customer experience-loyalty-consumer spend. Journal of Retailing and Consumer Services, 31, 277-286. https://doi.org/10.1016/j.jretconser.2016.04.009

Tabachnick, B. G. \& Fidell, L.S. (2007). Using Multivariate Statistics. Boston, MA: Allyn \& Bacon.

Verhoef, P. C., Lemon, K. N., Parasuraman, A., Roggeveen, A., Tsiros, M., \& Schlesinger, L. A. (2009). Customer experience creation: Determinants, dynamics and management strategies. Journal of Retailing, 85(1), 31-41. https://doi. org/ 10.1016/j.jretai.2008.11.001

Walker, J. T., Farren, G., Dotterweich, A., Gould, J., \& Walker, L. (2017). Fitness center service quality model confirmation SQAS-19. Journal of Park and Recreation Administration, 35(4), 49-58. https://doi.org/10.18666/JPRA-2017V35-I4-7922

Walls, A. (2009). An examination of consumer experience and relative effects on consumer values. Unpublished doctoral dissertation, University of Central Florida, Orlando, FL.

Walls, A. R., Okumus, F., Wang, Y. R., \& Kwun, D. J. W. (2011). An epistemological view of consumer experiences. International Journal of Hospitality Management, 30(1), 10-21. https://doi.org/10.1016/j.ijhm.2010.03.008

Wu, C. H. J. (2007). The impact of customer-to-customer interaction and customer homogeneity on customer satisfaction in tourism service-The service encounter prospective. Tourism Management, 28(6), 1518-1528. https://doi. org/10.1016/j.tourman.2007.02.002

Zeithaml, V. A., Berry, L. L., \& Parasuraman, A. (1996). The behavioral consequences of service quality. Journal of Marketing, 60(2), 31-46. https://doi.org/10.1177/002224299606000203

This is Open Access article distributed under the terms of CC-BY-NC-ND 4.0 International License.

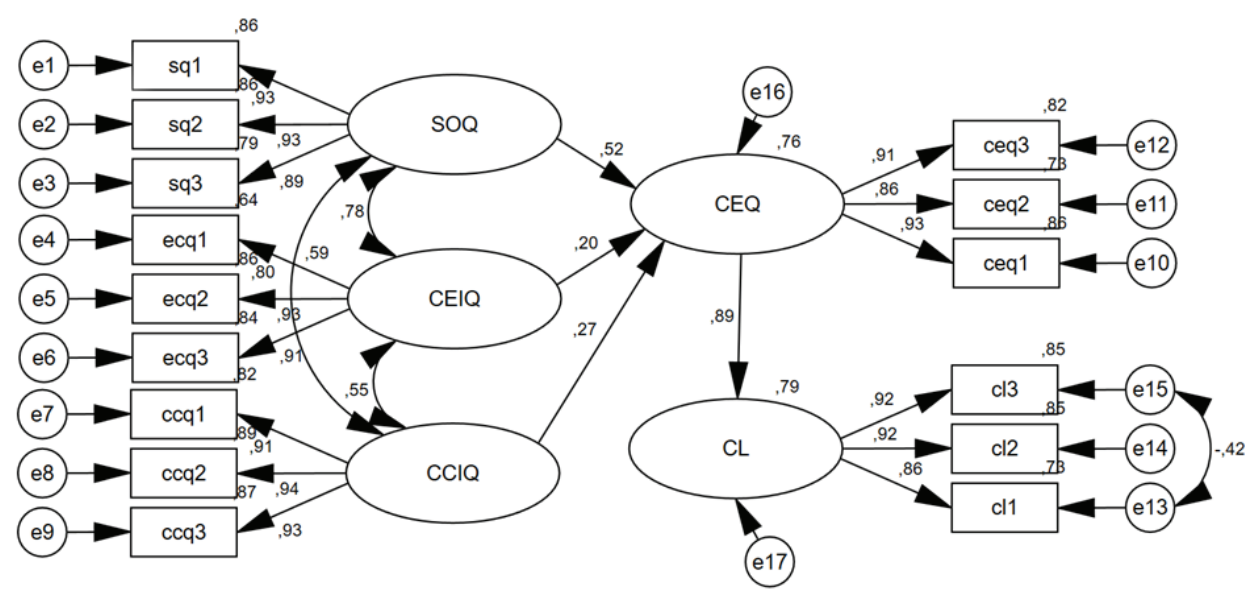

Suppl. Figure 1. The structural equation model demonstrates the relationship between service outcome quality (SOQ), customer-employee interaction quality (CEIQ), customer-customer interaction quality (CCIQ), customer experience quality (CEQ), and customer loyalty (CL) 
Suppl. Table 1. Standardized direct, indirect, and total effects

\begin{tabular}{|c|c|c|c|c|c|c|}
\hline \multirow{3}{*}{ Construct } & \multicolumn{6}{|c|}{ Standardized Effects } \\
\hline & \multicolumn{2}{|c|}{ Direct } & \multicolumn{2}{|c|}{ Indirect } & \multicolumn{2}{|c|}{ Total } \\
\hline & CEQ & $\mathrm{CL}$ & CEQ & $\mathrm{CL}$ & CEQ & $\mathrm{CL}$ \\
\hline SOQ & .516 & - & - & .458 & .516 & .458 \\
\hline CEIQ & .196 & - & - & .174 & .196 & .174 \\
\hline CCIQ & .269 & - & - & .239 & .269 & .239 \\
\hline CEQ & - & .887 & - & - & - & .887 \\
\hline
\end{tabular}

Suppl. Table 2. Survey items

Service outcome quality (Brady \& Cronin, 2001; Kim \& Choi, 2013; Mohr \& Bitner, 1995)

I would say that XYZ gives the requested outcome to the customers.

I believe that XYZ provides superior outcomes to its customers.

feel good about what XYZ provides to its customers.

Interaction quality (Brady \& Cronin, 2001; Kim \& Choi, 2013; Mohr \& Bitner, 1995)

I believe that XYZ and XYZ's employees are caring for the customers.

I would say that XYZ and XYZ's employees are interested in the customers.

I think that the quality of my interaction with XYZ and XYZ's employees is excellent.

Peer-to-peer quality ((Brady \& Cronin, 2001; Kim \& Choi, 2013; Lemke et al., 2010)

I think that total contact with other customers at XYZ is excellent.

I believe that we get superior interactions with other customers at XYZ.

I would say that the quality of my interaction with other customers at XYZ is excellent.

Customer experience quality ((Brady \& Cronin, 2001; Kim \& Choi, 2013; Lemke et al., 2010)

I think that the total experience procedure at XYZ is excellent.

I believe that we get a superior experience at XYZ.

I would say that the experience at XYZ is excellent.

Customer loyalty (Zeithaml et al, 1996)

$\mathrm{XYZ}$ is my first choice to buy fitness services.

I will continue to visit $\mathrm{XYZ}$ in the next years.

I will recommend XYZ services to others.

Note: All items were scored on a five-point Likert scale from "totally disagree" (1) to "completely agree" (5). 